\title{
Chlorhexidine delivery system from titanium/polybenzyl acrylate coating: Evaluation of cytotoxicity and early bacterial adhesion
}

\author{
María C. Cortizo ${ }^{a, b}$, Tamara G. Oberti ${ }^{a}$, María S. Cortizo $^{a, *}$, Ana M. Cortizo ${ }^{c}$, \\ Mónica A. Fernández Lorenzo de Mele ${ }^{a, d, *}$ \\ ${ }^{a}$ Instituto de Investigaciones Fisicoquímicas Teóricas y Aplicadas (INIFTA), Facultad de Ciencias Exactas, Universidad Nacional de La Plata, \\ CONICET, CCT-La Plata, 1900 La Plata, Argentina \\ ${ }^{\mathrm{b}}$ Materiales Dentales, Facultad de Odontología, Universidad Nacional de La Plata, 1900 La Plata, Argentina \\ ' GIOMM (Grupo de Investigación en Osteopatías y Metabolismo Mineral), Departamento de Ciencias Biológicas, Facultad de Ciencias Exactas, \\ Universidad Nacional de La Plata, 1900 La Plata, Argentina \\ ${ }^{\mathrm{d}}$ Facultad de Ingeniería, Universidad Nacional de La Plata, La Plata, Argentina
}

\section{A R T I C L E I N F O}

\section{Article history:}

Received 9 August 2011

Received in revised form

16 January 2012

Accepted 17 January 2012

Keywords:

Titanium

Dental implant

Acrylate

Chlorhexidine

Biocompatibility testing

Bacterial adhesion

\begin{abstract}
A B S T R A C T
Objectives: The formation of biofilms on titanium dental implants is one of the main causes of failure of these devices. Streptococci are considered early colonizers that alter local environment favouring growing conditions for other colonizers. Chlorhexidine (CHX) is so far the most effective antimicrobial treatment against a wide variety of Gram-positive and Gram-negative organisms as well as fungi. This study was designed to develop a CHX delivery system appropriate for healing caps and abutments, with suitable drug release rate, effective as antimicrobial agent, and free of cytotoxic effects.

Methods: Polybenzyl acrylate (PBA) coatings with and without CHX (Ti/PBA and Ti/PBA-CHX, respectively) and different drug loads $(0.35,0.70$, and $1.40 \%, \mathrm{w} / \mathrm{w})$ were assayed. The cytotoxic effect of CHX released from the different substrates on UMR106 cells was tested by alkaline phosphatase specific activity (ALP), and microscopic evaluation of the cells. Noncytotoxic drug load $(0.35 \%, \mathrm{w} / \mathrm{w})$ was selected to evaluate the antimicrobial effectiveness of the system using a microbial consortium of Streptococcus species.

Results: The kinetic profile of CHX delivered by Ti/PBA-CHX showed an initial fast release rate followed by a monotonic increase of delivered mass over $48 \mathrm{~h}$. The number of attached bacteria decreased in the following order: $\mathrm{Ti}>\mathrm{Ti} / \mathrm{PBA}>\mathrm{Ti} / \mathrm{PBA}-0.35$.

Conclusions: PBA- 0.35 coating is effective to inhibit the adhesion of early colonizers on $\mathrm{Ti}$ without any cytotoxic effect on UMR-106 cells.
\end{abstract}

(C) 2012 Elsevier Ltd. All rights reserved.

\section{Introduction}

Initial bacterial adhesion and colonization of healing caps, abutments and dental implant surfaces play a key role in biomaterial-related infections. ${ }^{1,2}$ Oral microorganisms are able to colonize biomaterial implant surfaces and related devices during surgery (perioperative contamination). Fürst et al. $^{3}$ demonstrated that the submucosal dental implant microbiota is already established at the completion of the

\footnotetext{
${ }^{*}$ Corresponding authors at: Instituto de Investigaciones Fisicoquímicas Teóricas y Aplicadas (INIFTA), Facultad de Ciencias Exactas, Universidad Nacional de La Plata, La Plata, Argentina. Tel.: +54 221425 7430; fax: +54 2214254642.

E-mail addresses: gcortizo@inifta.unlp.edu.ar (M.S. Cortizo), mmele@inifta.unlp.edu.ar (M.A. Fernández Lorenzo de Mele). 0300-5712/\$ - see front matter (C) 2012 Elsevier Ltd. All rights reserved. doi:10.1016/j.jdent.2012.01.008
} 
surgical procedure. Actinomyces species and Streptococci are considered early colonizers that alter the local environment preparing the surroundings for later colonizers that require more demanding growth conditions. ${ }^{1,4}$ Since Streptococci usually coadhere with $P$. gingivalis, their presence allow presume the eventual development of periodontitis. Streptococcus gordoni, for example, is able to extract and accumulate divalent cations in vivo, which may be a critical factor for the successful colonization of oral surfaces and communication with other microbial residents. Other bacteria which bind to Streptococci, such as Fusobacterium, Capnocytophaga, and Prevotella species, are also known to be involved in periodontal infections.

Microbial analyses of failed implants ${ }^{5}$ showed the presence of Streptococcus anginosus (milleri) and Fusobacterium nucleatum in $70 \%$ of cases. Additionally, in all but one implant (97\%), bacterial growth was found on the implant surface. The implant (or fixture) showed to be 100 to 1000 times more effective as bacteriological sample source than the scoop samples of sockets.

Difficulty of antibiotic treatments to eradicate oral infections is known to be related to a significant decrease in the susceptibility to biocidal agents of biofilms, compared with cultures grown in suspension (planktonic cells). ${ }^{3,6,7}$ The high cell density of microbial biofilms is associated to their higher antimicrobial resistance. Mechanical management to remove the biofilm in the peri-implant vicinity is almost impossible since the roughness and composition of the implant surface, which modulate osteoblast attachment and proliferation, should not be altered. The application of biocidal agents by means of controlled delivery seems to be a suitable alternative. Chlorhexidine ( $\mathrm{CHX}$ ) and its water-soluble derivative chlorhexidine digluconate have been extensively used to control biofilms on teeth. ${ }^{8,9} \mathrm{CHX}$ is so far the most effective antimicrobial treatment because of its several advantages: high antimicrobial capability, and ability to inhibit glycosydic and proteolytic activities and reduce matrix metal-proteinase action in most oral bacteria. ${ }^{10} \mathrm{CHX}$ is also effective against a wide variety of Gram-positive and Gram-negative organisms as well as fungi. ${ }^{11}$ Additionally, it is retained by the dentine hard tissues and is an effective irrigator to prevent root canal reinfection due to coronal leakage. ${ }^{12} \mathrm{CHX}$ does not negatively affect the push-out bond strength in post bond cementation. ${ }^{13}$

Unfortunately this compound has been reported to induce cytotoxicity ${ }^{14}$ and genotoxicity in oral tissue cells, preventing fibroblast attachment, reducing their proliferation, inducing DNA damage and other genotoxic side effects, thus negatively interfering the early healing phase. ${ }^{15}$ However, biofilms are characterized by a microscale spatial, structural, and functional heterogeneity that may change to become more resistant when $\mathrm{CHX}$ is present in the biological fluid. ${ }^{16}$ This highlights the importance of a drug release system on the dental implant surfaces, healing caps and abutments in order to hinder early bacterial attachment and the subsequent biofilm development favouring antimicrobial action against the early less dense biofilm.

Current research on properties of titanium implant and related devices focuses on two main purposes: to accelerate bone healing and prevent bacterial attachment. ${ }^{4}$ Over a period of several days, CHX adsorption to titanium dioxide (anatase and rutile) proved to be more rapid on rutile and desorption on anatese. ${ }^{17}$ Polymer coatings also seem to be suitable to control the release rate of antimicrobial drugs. Promising results on the antimicrobial properties of biochemically modified collagen coated titanium were also reported. ${ }^{18}$ Moreover, several studies have suggested a controlled release drug device with water-permeable polymer for antimicrobials delivery. ${ }^{19,20}$ However, the development of suitable drug carriers for prolonged release of CHX still remains a challenge. Further studies are needed to evaluate the release rate, antimicrobial effects, and the cytotoxicity of controlled drug release devices. ${ }^{11,18}$

During the last decades, polymeric materials have significantly contributed to the development and improvement of implant and related devices ${ }^{21-23}$ as well as drug delivery systems. ${ }^{24-26}$ Amongst them, metha/acrylic polymers exhibit good adhesion to metal surfaces ${ }^{27}$ and resistance to enzymatic hydrolysis, and may be good candidates for osseointegrated interfaces. This last condition is crucial because the clinical success of oral implants depends on their early osseointegration, which is in turn related to implant-tissue interaction. ${ }^{28}$ The chlorhexidine coating was designed to inhibit the adhesion of bacteria on healing caps and abutments (very close to the dental implant). However, the coating may release the drug towards both fibroblastic and osteoblastic surrounding tissues. Considering that the lack of adherence of osteoblasts is the main cause of failure of the implants, cytotoxicity assays were performed with an osteosarcoma (UMR106) cell line to investigate if these osteoblastic cells were affected by the release of the drug from the surrounding region. The effects, if any, would be reflected by the decrease of alkaline phosphatase production and/or the inhibition of cell growth. UMR-106 cells have been widely used for the evaluation of cytotoxicity of different compounds of clinical interest during the last two decades. ${ }^{29-31}$

On the basis of previous observations on the key role of early biofilm formation in implant-related infections, the present study was designed to find a CHX drug delivery system with suitable antiadherent properties and drug release rate, effective as antimicrobial agent during the initial bacterial adhesion, and free of cytotoxic effects. Thus, CHX-containing titanium/polybenzyl acrylate coatings (Ti/PBA-CHX) with different drug loads were used. First, the cytotoxic effect of CHX released from different samples was tested in UMR106 cells in order to select the suitable non-cytotoxic drug load. Subsequently, the antimicrobial effectiveness of the selected Ti/PBA-CHX coating was evaluated using a microbial consortium of Streptoccoccus.

\section{Materials and methods}

\subsection{Materials}

Grade I titanium samples $(10 \mathrm{~mm} \times 20 \mathrm{~mm} \times 1 \mathrm{~mm})$ were used as substrate. Samples were pretreated by polishing down to alumina $1 \mu \mathrm{m}$ size; subsequently they were degreased with acetone, and rinsed in distilled water.

Polybenzyl acrylate (PBA) was synthetized by radical polymerization under microwave conditions as previously 
described. ${ }^{32}$ Average molecular weight $\left(M_{\mathrm{w}}\right)$ and polydispersity index $\left(M_{w} / M_{n}\right)$ of the sample used in this study were 91370 and 2.6, respectively.

Chlorhexidine (CHX, from Aldrich), and chloroform (Carlo Erba, PA) were used unmodified. The composition of the phosphate buffer solution (PBS) was the following: $\mathrm{NaCl} 8.0 \mathrm{~g} /$ $\mathrm{L} ; \mathrm{K}_{2} \mathrm{HPO}_{4} 1.4 \mathrm{~g} / \mathrm{L} ; \mathrm{KH}_{2} \mathrm{PO}_{4} 0.34 \mathrm{~g} / \mathrm{L}, \mathrm{pH} 7.4$.

\subsection{Coating preparation}

Polymer films were prepared by solvent casting methodologies: a PBA solution (alone or with CHX) was prepared in chloroform ( $5 \%, \mathrm{w} / \mathrm{v}$ ) and poured onto Ti samples. The solvent was left at room temperature to evaporate, and the resulting films were then dried under vacuum until constant weight. The coating was sterilized by autoclaving for $30 \mathrm{~min}$ before use. Three CHX concentrations were tested: $0.35,0.70$, and $1.40 \%(\mathrm{w} / \mathrm{w})$ and the corresponding samples were assigned as Ti/PBA-0.35, Ti/PBA-0.7, and Ti/PBA-1.4, respectively.

\subsection{Cell culture and differentiation assay}

UMR106 rat osteosarcoma cells were grown in DMEM containing 10\% FBS, $100 \mathrm{U} / \mathrm{mL}$ penicillin, and $100 \mu \mathrm{g} / \mathrm{mL}$ streptomycin at $37{ }^{\circ} \mathrm{C}$ in a $5 \% \mathrm{CO}_{2}$ atmosphere. ${ }^{33}$ Cells were seeded in sixwell plates with $\mathrm{Ti}$, Ti/PBA, or Ti/PBA-CHX coating samples at $10^{5}$ cells $/ \mathrm{mL}$ density, and incubated for $24 \mathrm{~h}$. At the end of this incubation period, osteoblasts adhered to plastic wells were washed with PBS, fixed with methanol, stained with Giemsa, and evaluated by optical microscopy, as previously described. ${ }^{34}$ The number of cells was counted in ten representative fields/well. Cell morphology was evaluated using a BX51 Olympus microscope and a DP Controller image processor. Alkaline phosphatase specific activity (ALP), a marker of osteoblastic phenotype, was determined. The cell layer was washed with PBS and solubilized in $0.1 \%$ TritonX-100. Aliquots of the total cell extract were used for protein determination by the Bradford technique. ${ }^{35}$ ALP was measured by spectrophotometric determination of hydrolysis initial rates of $p$ nitrophenyl phosphate ( $p$-NPP) to $p$-nitrophenol $(p-\mathrm{NP})$ at $37^{\circ} \mathrm{C}$ for $10 \mathrm{~min}$. The formation of the product was assessed by the absorbance at $405 \mathrm{~nm}$.

\subsection{Bacterial adhesion}

A bacterial consortium collected from the oral cavity of several patients with normal periodontal condition was used in the experiments. Informed consent was requested from each patient following the recommendations of the Ethical Committee of the University of La Plata. Samples were obtained by scraping the gingival area of buccal and lingual tooth surfaces. Each sample was dispersed by sonication for $10 \mathrm{~s}$ in PBS. Oral microorganisms were cultured in modified Mitis-Salivarius liquid medium (MSL) to isolate Streptococcus mitis (S. mitis) and S. salivarius. ${ }^{36}$ The initial number of cells was adjusted to ca. $10^{5}$ cells/mL. Samples of Ti, Ti/PBA, and Ti/PBA-CHX were immersed in Erlenmeyer flasks containing a bacterial culture in order to allow biofilm formation during 2 days. For direct counts, the samples with biofilms were removed from the bacterial culture, rinsed with $\mathrm{PBS}$ to remove loose cells, stained with $0.01 \%$ acrydine orange for $5 \mathrm{~min}$, and examined under ultraviolet light by epifluorescence microscopy. Images were recorded and analyzed using a BX51 Olympus fluorescence microscope and a DP Controller image processor.

Some Ti/PBA-0.35 samples together with $\mathrm{Ti}$ and Ti/PBA (controls) were immersed for $48 \mathrm{~h}$ in PBS (Ti/PBA-0.35-48 h) in order to allow the release of CHX from Ti/PBA-0.35. Then the samples were dipped into the culture media inoculated with bacteria, and microbial adhesion was analyzed after 2- and 7day periods (Ti/PBA-0.35-48 h-2 d; Ti/PBA-0.35-48 h-7 d, respectively) on surfaces characterized by the lowest $\mathrm{CHX}$ release rate from $\mathrm{Ti} / \mathrm{PBA}-0.35-48 \mathrm{~h}$ in relation to the release rate of fresh Ti/PBA-0.35 samples.

\subsection{Chlorhexidine release kinetics}

Drug release experiments with Ti samples were carried out in tubes containing $5 \mathrm{ml} \mathrm{PBS}$ ( $\mathrm{pH} 7.4$ ), at $37^{\circ} \mathrm{C}$. At appropriate times, the supernatants were removed and replaced by $5 \mathrm{ml}$ fresh buffer. The time-dependent release of the drug was followed by monitoring the amount of CHX present in the supernatant medium, using a double-bean on a Cary 3 (Varian, Australia) spectrophotometer with $1 \mathrm{~cm}$ optical path cell $\left(\lambda_{\max }=254 \mathrm{~nm}\right)$. A linear calibration curve of CHX concentration versus absorbance at $254 \mathrm{~nm}$ was obtained using CHX standards at $0-50 \mu \mathrm{g} / \mathrm{ml}$ range.

\subsection{Statistical analysis}

For each experimental condition at least three separate experiments were performed. Data were expressed as the mean \pm standard deviation. Statistical differences amongst the groups were assessed by the one-way ANOVA test with Tukey-Kramer Multiple Comparisons. A $<0.05 p$ value was considered significant for all statistical analyses.

\section{Results}

\subsection{Cytotoxicity assay}

In order to investigate the effect of $\mathrm{CHX}$ addition on the cytotoxicity of substrates, UMR106 osteoblastic cells were used to study proliferation and differentiation on different substrates. Fig. 1A-E shows the aspect of the surviving UMR106 cells in wells containing different substrates after $24 \mathrm{~h}$. As previously described, ${ }^{37}$ cells growing on standard tissue culture polystyrene dishes with a Ti sample (Fig. 1A) exhibited a polygonal morphology with cytoplasmic processes connecting cells. Nuclei were well stained and showed kidney-jarring aspect. Mitotic figures were also evident under this culture condition. After $24 \mathrm{~h}$ in culture, cells exposed to Ti/PBA showed no morphological changes (Fig. 1B). When cells were cultured in presence of Ti/PBA-0.35, a few vacuolated cells with otherwise normal culture were observed (Fig. 1C). On the other hand, higher $\mathrm{CHX}$ concentrations (0.7 and 1.4\%) in the Ti/ PBA samples induced important morphological changes, showing shrinkage, smaller and pyknotic cells, and loss of cytoplasmic processes, suggesting cytotoxic effects (Fig. 1D and $\mathrm{E})$. 

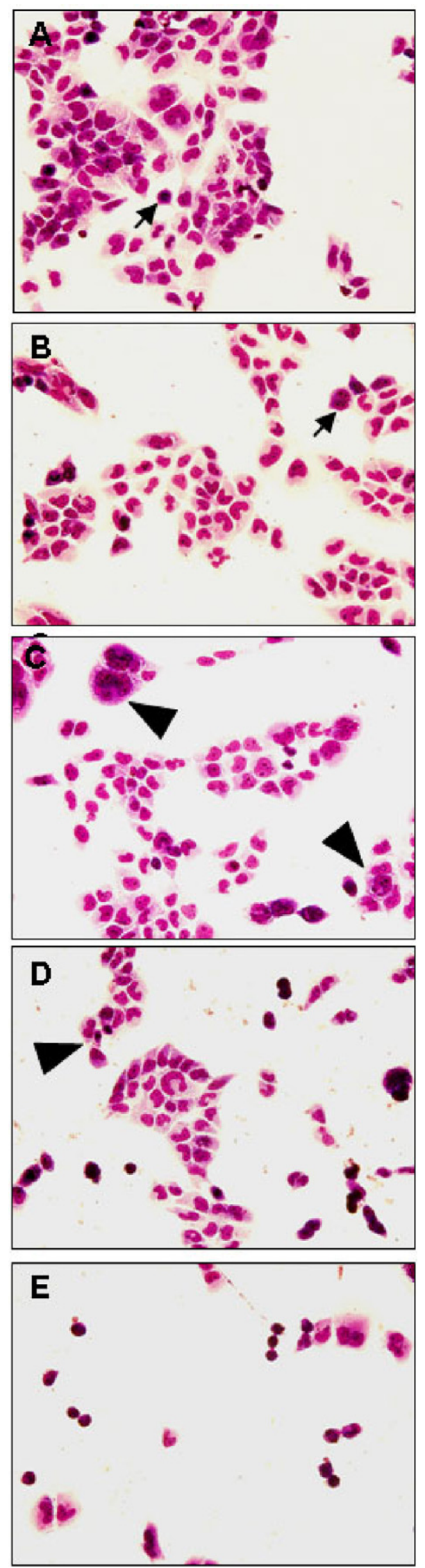

Fig. 1 - Effect of different Ti samples on UMR106 cell morphology. Cells were seeded in standard tissue culture wells in presence of Ti (A), Ti/PBA (B), Ti/PBA-0.35 (C),
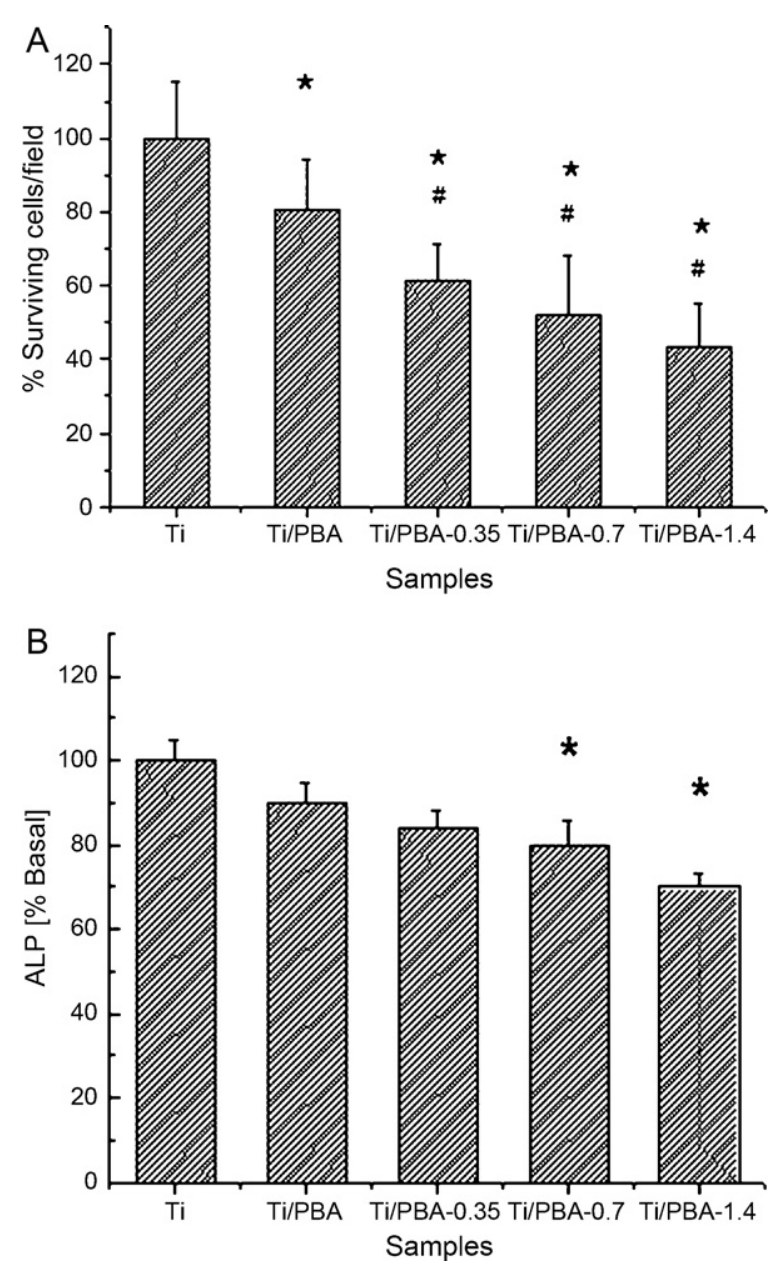

Fig. 2 - Effect of the substrate on the number of surviving cells (A) and ALP activity (B). UMR106 cells were cultured in presence of different substrates for $24 \mathrm{~h}$. Values are shown as the mean \pm SEM. ${ }^{*} p<0.05$ versus Ti sample; ${ }^{\#} p<0.05$ versus Ti/PBA sample.

To further confirm the effect of CHX, the number of surviving cells in culture after $24 \mathrm{~h}$ incubation under different conditions was counted (Fig. 2A). When cells were cultured in presence of the Ti/PBA samples, a small but statistically significant decrease ( $80 \%$ of control) in the cell number was found in comparison with the Ti control. Furthermore, a dosedependent inhibition of CHX on the cell number was observed in comparison with $\mathrm{Ti}$ and Ti/PBA cultures $(p<0.05)$. Fig. 2B shows ALP activity; this marker of osteoblastic phenotype was not affected by the incubation in presence of Ti/PBA and Ti/ PBA-0.35 samples. However, highest concentrations of $\mathrm{CHX}$ (0.7 and 1.4\%) in the samples induced a significant decrease in ALP activity (Fig. 2B).

Ti/PBA-0.7 (D), and Ti/PBA-1.4 (E), and cultured for $24 \mathrm{~h}$. After this incubation period, cells were stained with Giemsa, observed, and photographed. Mitotic figures (arrow) and vacuolated cells (arrow head) are indicated. 
A

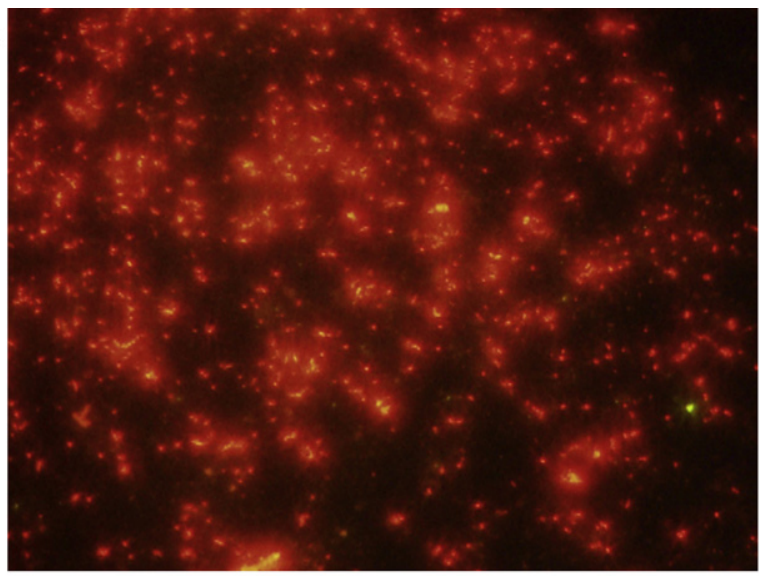

C

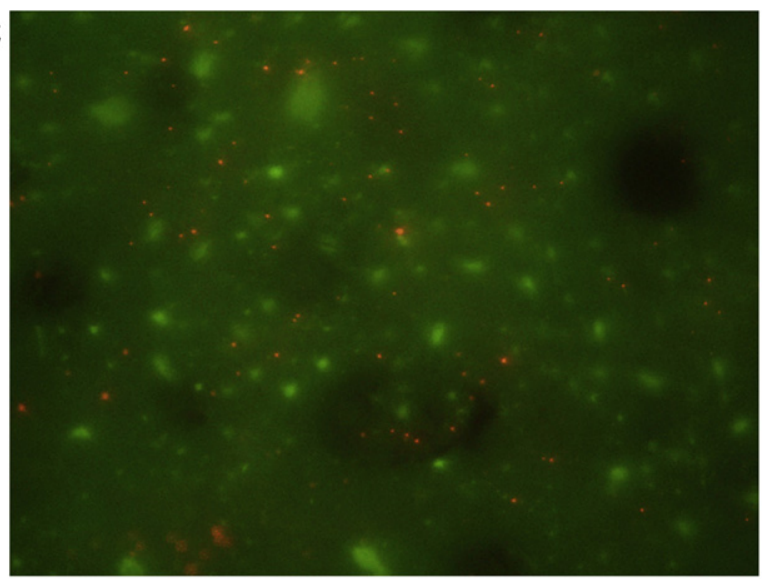

$\mathrm{B}$

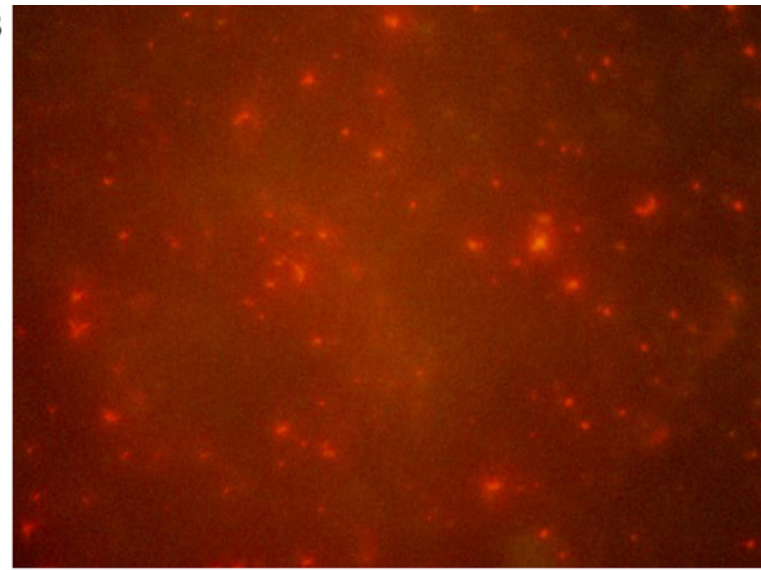

D

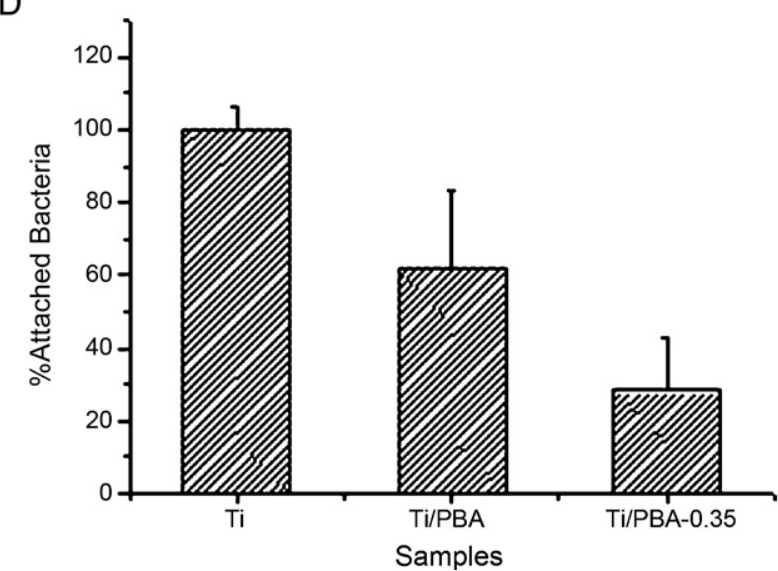

Fig. 3 - Bacterial adhesion to Ti (A), Ti/PBA (B), and Ti/PBA-0.35 (C). Percentage of bacterial adhesion to Ti (A), Ti/PBA (B), and Ti/PBA-0.35 (C). Ti is the control surface (100\%) (D).

\subsection{Bacterial adhesion}

Because of its better compatibility with cells, we evaluated bacterial adhesion on the Ti/PBA sample containing the lowest CHX concentration (Ti/PBA-0.35). Fig. 3A-C shows epifluorescence microscopy images corresponding to $\mathrm{Ti}$, Ti/PBA, and Ti/PBA- 0.35 respectively. As observed, the number of bacteria decreased in the order $\mathrm{Ti}>\mathrm{Ti} / \mathrm{PBA}>\mathrm{Ti} / \mathrm{PBA}-0.35$. Significant differences between Ti and Ti/PBA $(p<0.001)$, Ti and Ti/PBA$0.35(p<0.001)$, and Ti/PBA and Ti/PBA-0.35 $(p<0.01)$ were found.

\subsection{Chlorhexidine release kinetics}

A kinetic study was carried out to evaluate the rate of $\mathrm{CHX}$ release from the Ti/PBA samples. Fig. 4 shows the time course of the percentage of drug released from $0.35 \% \mathrm{CHX}$-coated $\mathrm{Ti} /$ PBA. The kinetic profile showed an initial fast release rate followed by a monotonic increase of mass delivery over $36 \mathrm{~h}$. In order to analyze experimental data, the diffusion of the drug from a polymeric film of $\mathrm{L}$ thickness was considered and a

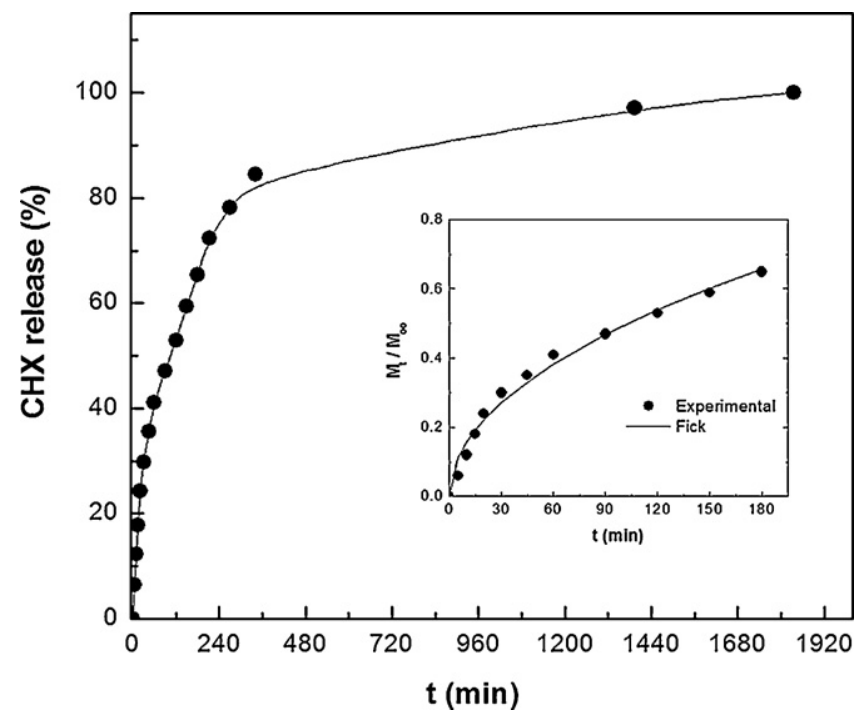

Fig. 4 - Percentage of chlorhexidine released from Ti/PBA0.35 coating. Release study was carried out in PBS buffer at $37{ }^{\circ}$. Inset indicates the fit according to Eq. (1). 
power law model was applied..$^{38,39}$ The following expression was used to fit data:

$\frac{M_{t}}{M_{\infty}}=4\left(\frac{D t}{\pi L^{2}}\right)^{n}=k t^{n}$

where $M_{t}$ is the cumulative mass of drug released at time $t ; M_{\infty}$ is the mass of drug in the film; $D$ is the diffusion coefficient; and $n$ is an exponent which indicates the nature of the release mechanism. In this study, fitting values were $n=0.497 \pm 0.027$, and $\mathrm{D}=3.3 \times 10^{-9} \mathrm{~cm}^{2} \mathrm{~s}^{-1}\left(\mathrm{R}^{2}=0.986\right)$. Results are presented in the inset of Fig. 4.

\subsection{Bacterial adhesion on Ti/PBA-0.35 after partial release of $\mathrm{CHX}$}

In order to determine the grade of inhibition in bacterial adherence on Ti/PBA- 0.35 after $48 \mathrm{~h}$ wash-out phase, bacterial adherence test was repeated in samples previously immersed in PBS for $48 \mathrm{~h}$ (Ti/PBA-0.35-48 h). Ti-48 $\mathrm{h}$ and Ti/PBA-48 $\mathrm{h}$ were used as controls. Ti-48 h, Ti/PBA-48 h, and Ti/PBA-0.35-48 h samples were subsequently immersed in the culture media inoculated with bacteria, and bacterial adherence was quantified after 2 and 7 days immersion (Ti-48 h-2 d, Ti/ PBA-48 h-2 d, Ti/PBA-0.35-48 h-2 d, and Ti-48 h-7 d, Ti/PBA48 h-7 d, Ti/PBA-0.35-48 h-7 d, respectively).

Fig. 5 shows bacterial adhesion for Ti- $48 \mathrm{~h}-2 \mathrm{~d}, \mathrm{Ti} / \mathrm{PBA}-$ $48 \mathrm{~h}-2 \mathrm{~d}$, and Ti/PBA-0.35-48 h-2 d. Indeed, though a high percent of the CHX had been released from the Ti/PBA-0.35$48 \mathrm{~h}$ during immersion in PBS, bacterial adherence was notably reduced in relation to Ti-48 $\mathrm{h}$ after 2 days immersion in the culture medium. Additionally, comparison of the attachment on Ti-48 h-2 d and Ti/PBA-48 h-2 d showed that PBA coating, without CHX addition, also hinders bacterial attachment considerably. Highly significant differences $(p<0.001)$ between Ti-48 h-2 d and both Ti/PBA-48 h-2 d and Ti/PBA-0.35-48 h-2 d were found.

Experiments with a 7-day immersion period in the culture medium were also assayed (Ti/PBA-0.35-7 d). Higher bacterial adherence on all samples was observed with respect to 2 days

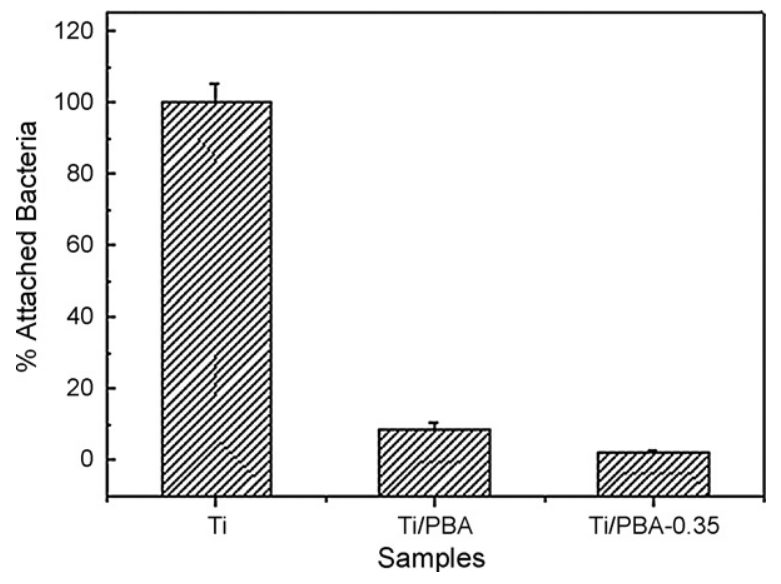

Fig. 5 - Percentage of bacterial adhesion to Ti (A), Ti/PBA (B), and Ti/PBA-0.35 (C) after immersion in PBS for $48 \mathrm{~h}$ (washing up period) and then in the culture medium for 2 days. $\mathrm{Ti}$ is the control surface (100\%). Values are shown as the mean \pm SEM. exposure for Ti-48 h-7 d, Ti/PBA-48 h-7 d, Ti/PBA-0.35-48 h7 d (403/field (100\%); 116.3/field (29\%); 110.2/field (27\%). Again, the number of bacteria shows the following decreasing order: Ti-48 h-7 d $\gg$ Ti/PBA-48 h-7 d > Ti/PBA-0.35-48 h-7 d, with significant differences between Ti-48 h-7 $\mathrm{d}$ and both Ti/PBA$48 \mathrm{~h}-7 \mathrm{~d}$ and Ti/PBA-0.35-48 h-7 d $(p<0.05)$.

\section{Discussion}

Titanium (Ti) and its alloys have proved to be very suitable as dental implant materials. ${ }^{40-42}$ However, two main aspects should be improved: increase of the rate of bone healing and inhibition of bacterial adherence. In this study a PBA-coating on Ti substrate was developed in order to explore its efficacy to inhibit the initial streptococci adhesion on osteoblast cultures without cytotoxic effects. PBA has been already employed in coatings of different materials, but not for biological applications. ${ }^{27}$ Our results showed a promising future for the application of this polymer since only a small decrease in cell proliferation on Ti/PBA was observed, without affecting the cell morphology or ALP activity. Moreover, according to our results, the addition of a low dose of $\mathrm{CHX}$ in $\mathrm{PBA} / \mathrm{Ti}$ samples implied a slight decrease in the cell number without significant alterations in the cell morphology or ALP activity. In agreement, surfaces coated with other polymers have been reported to attach cells such as fibroblasts and osteoblasts whilst showing reduced S. aureus adhesion. This selective biointeraction pattern may be quite useful for osteosynthesis, orthopaedic, and dental implantology ${ }^{43}$ applications.

CHX is an effective antimicrobial agent because of its several advantages: high antimicrobial action (effective against a wide variety of Gram-positive and Gram-negative organisms), and ability to inhibit gycosydic and proteolytic activities and reduce matrix metal-proteinase activities in most oral bacteria ${ }^{10}$ as well as fungi. ${ }^{11}$ Moreover, it is retained by the dentine hard tissues and is an effective irrigator to prevent root canal reinfection due to coronal leakage. ${ }^{11,12}$ Nevertheless, several studies demonstrated that this compound may induce adverse effects. ${ }^{14}$ Giannelli et al. ${ }^{15}$ suggested that direct application of $\mathrm{CHX}$ during regenerative therapy for the treatment of peri-implant diseases could exert serious toxic effects on gingival fibroblast, endothelial cells, and especially on alveolar osteoblasts, thus negatively interfering the early healing phase of these oral infections.

Our studies demonstrated that the biocidal effect is dose dependent. In fact, when $1.4 \%$ and $0.7 \%$ CHX loads were employed, harmful signals were found, including morphological changes, shrinkage, smaller and pyknotic cells, and loss of cytoplasmic processes which suggest cytotoxic effects. Conversely, assays with $0.35 \% \mathrm{CHX}$ did not show such effects.

The analysis of the CHX release profile from Ti/PBA coating indicated that the main mechanism regulating drug delivery at short times is diffusion $(n \sim 0.5)$, whilst at longer times a monotonic increase of the accumulative release $\mathrm{CHX}$ suggested that the release process is affected by complementary effects. In this last case, polymer swelling (dynamic expansion) involving the transition from a semi-rigid to a more flexible state is surely the process that accompanies and favours CHX release. ${ }^{39}$ Our results showed that CHX 
inhibits streptococci attachment and the subsequent biofilm formation.

It has been demonstrated that initial colonizers play a key role in biofilm formation, preparing the surroundings for later colonizers. ${ }^{4}$ Consequently, the inhibition of their adherence is a hindrance for the growth of more demanding bacteria.

Biofilm structure protects bacteria against the action of many antimicrobial agents. Consequently, studies on drug delivery in planktonic cells should not be extrapolated to bacterial biofilms. The mechanisms of resistance to antibiotics in bacterial biofilms are beginning to be elucidated. They include: slow penetration (antibiotics fail to penetrate beyond the surface layers of biofilm), resistant phenotype (some of the bacteria may differentiate into a protective phenotypic state), and altered microenvironments (antibiotic action may be antagonized in zones of nutrient depletion or waste product accumulation). ${ }^{44}$ Thus, preventing the adhesion and aggregation of bacteria prior to biofilm formation on the surface seems to be a better strategy than treating the mature biofilm.

Biofilm development is initiated by planktonic bacteria that attach to the surface first reversibly and then irreversibly. Adhesion is usually promoted by the previous adsorption of organic substances onto the surface (forming a thin layer known as "conditioning film"). Pioneer microorganisms may adapt their attachment strategies according to the nature of the surface. At this stage, bacteria are still susceptible to antibiotics. Subsequently, aggregation occurs, and the production of extracellular polymeric materials by bacteria changes the physicochemical characteristics of the surface. Thus, the growth of bacterial biofilm on non-toxic substrates is largely independent of their composition but dependent on microroughness. ${ }^{45-47}$

In order to prevent early bacterial adhesion, the correlation of surface properties (surface charge, roughness, and energy) of the substrate and bacteria must be assessed. However, this is still a controversial matter. Li and Logan, ${ }^{48}$ working with 8 bacterium strains and 11 surfaces of different composition, observed much greater correlation of adhesion with surface energy (based on three liquid contact angles) than surface charge for the different surfaces. Other researchers reported that surface properties do not seem to correlate with the grade of adhesion of Streptococcus Mutans on dental materials. ${ }^{49}$ Müller et al., ${ }^{50}$ demonstrated that proteins adsorbed from physiological fluids, such as serum and saliva, are able to significantly alter the physicochemical properties of underlying surfaces, which in turn greatly influences subsequent early bacterial aggregation. Protein layers generated by adsorption from physiological fluid increased or decreased Streptoccocus adhesion depending on the type of protein film and bacterial strain examined.

Contact angles of coatings prepared with aliphatic and aromatic methacrylates with methyl methacrylate (MMA) were found between $55^{\circ}$ and $79^{\circ}$, showing similar or higher hydrophobia than titanium $\left(53^{\circ}\right) .{ }^{51}$ Thus, according to some authors, a higher bacterial adhesion may be expected for the most hydrophobic PBA surface than for bare titanium. ${ }^{52}$ However, our results showed lower adhesion when titanium was covered by the polymer. This supports the assumption that there is no simple relationship to correlate bacterial properties and surface energy of a substratum immersed in a protein-containing medium with bacterial adhesion. ${ }^{46}$
There are two main approaches to prevent foreign body infections from affecting the interaction between biomaterial and bacterium: (1) development of polymers or polymer surfaces with antiadhesive properties; (2) development of polymers or polymer surfaces with antimicrobial properties. ${ }^{22}$ Our results demonstrated that during the first two days, the effect of antimicrobial release and polymer antiadhesive properties are additive. After $48 \mathrm{~h}$, the effect of the surface properties of the polymer is dominant.

To explain this behaviour it should be considered that several properties of the polymer, such as the glass transition temperature $\left(T_{g}\right)$, molecular mobility of the drug, miscibility between the drug and excipients, and the rate and extent of drug crystallization, may influence bacterial adherence. ${ }^{53}$ Amongst them, $T_{g}$ is the characteristic temperature above which the mobility of the polymer chains is markedly increased, leading to much higher mass transfer rates of water and drug. In our case, $\mathrm{T}_{\mathrm{g}}$ for $\mathrm{PBA}$ is $6^{\circ} \mathrm{C}$, indicating that the polymer is in rubbery state and so, a significant amount of water diffuses slowly into the hydrophobic membrane. This effect could lead to the formation of channels resulting from changes in the polymer free volume, facilitating water diffusion. These changes in the structure of the film could explain the decrease in the bacterial adherence observed after the $48 \mathrm{~h}$ washing up period. Similar behaviour has been observed in other systems in which a hydrophobic membrane was studied. ${ }^{54}$

After immersion periods in the culture medium longer than 2 days, bacterial adherence increased on Ti-PBA-48 $\mathrm{h}$ and TiPBA-0.35-48 h, probably due to the production of extracellular polymeric substances by the bacteria which made the surface more compatible.

\section{Conclusion}

Overall, CHX delivery system from titanium/polybenzyl acrylate coating was designed and evaluated as inhibitor of early streptococci adhesion on healing cups and abutments. Results showed that the lowest concentration assayed $(0.35 \%$, $\mathrm{w} / \mathrm{w})$ was an effective antibacterial system without cytotoxic effects, particularly useful for these devices. A diffusion mechanism allowed the controlled delivery of the drug.

The inhibition of bacterial adherence was associated to two factors: the antimicrobial effect of the released $\mathrm{CHX}$ and the antiadhesive properties of the polymer. Our results demonstrated additive effects of these two factors during the first two days. However, after this period, the effect of the surface properties of the polymer is dominant.

Inhibition of the adhesion of early colonizers of the dental plaque is relevant because it prevents the attachment of later colonizers that require more demanding growth conditions. Consequently, the reduction of pioneer bacterial attachment impacts on the successive stages of biofilm formation with an overall effect on the oral health of the host.

\section{Acknowledgements}

This work was supported by Universidad Nacional de La Plata, Argentina (Projects X515, I129), CONICET and ANPCyT (PAE 
22398, PAE 22771, BID 1708 OC/AR, PICT 2010-1779; CIC-PBA and Proyect X514 (to AMC). AMC is a member of carrera del Investigador CIC-PBA.

\section{R E F E R E N C E S}

1. Busscher H, Rinastiti M, Siswomihardjo W, van der Mei HC. Biofilm formation on dental restorative and implant materials. Journal of Dental Research 2010;89:657-65.

2. Heuer W, Elter C, Demling A, Neumann A, Suerbaum S, Hannig M, et al. Analysis of early biofilm formation on oral implants in man. Journal of Oral Rehabilitation 2007;34:377-82.

3. Fürst MM, Salvi GE, Lang NP, Persson GR. Bacterial colonization immediately after installation on oral titanium implants. Clinical Oral Implants Research 2007;18:501-8.

4. Li J, Helmerhorst EJ, Leone CW, Troxler RF, Yaskell T, Haffajee $\mathrm{AD}$, et al. Identification of early microbial colonizers in human dental biofilm. Journal of Applied Microbiology 2004;97:1311-8.

5. Laine P, Salo A, Kontio R, Ylijoki S, Lindqvist C, Suuronen R. Failed dental implants-clinical, radiological and bacteriological findings in 17 patients. Journal of CranioMaxillofacial Surgery 2005;33:212-7.

6. Høiby N, Bjarnsholt T, Givskov M, Molin S, Ciofu O. Antibiotic resistance of bacterial biofilms. International Journal of Antimicrobial Agents 2010;35:322-32.

7. Costerton JW, Montanaro L, Arciola CR. Biofilm in implant infections: its production and regulation. International Journal of Artificial Organs 2005;28:1062-8.

8. Mandel ID. Antimicrobial mouthrinses: overview and update. The Journal of the American Dental Association 1994;125(Suppl 2):2S-10S.

9. Magnusson I. Local delivery of antimicrobial agents for the treatment of periodontitis. Compendium of Continuing Education in Dentistry 1998;19:953-6.

10. Cronan CA, Potempa J, Travis J, Mayo JA. Inhibition of Porphyromonas gingivalis proteinases (gingipains) by CHX: synergistic effect of $\mathrm{Zn}$ (II). Oral Microbiology and Immunology 2006;21:212-7.

11. Lee DY, Spångberg LS, Bok YB, Lee CY, Kum KY. The sustaining effect of three polymers on the release of chlorhexidine from a controlled release drug device for root canal disinfection. Oral Surgery Oral Medicine Oral Pathology Oral Radiology and Endodontology 2005;100:105-11.

12. Jung $\mathrm{S}$, Safavi $\mathrm{K}$, Spångberg L. The effectiveness of chlorhexidine in the prevention of root canal reinfection. Journal of Endodontics 1999;25:288.

13. Lindblad R, Lippo V, Lassila V, Salo S, Vallittu P, Tiäderhane L. Effect of chlorhexidine on initial adhesion of fiber-reinforced post to root canal. Journal of Dentistry 2010;38:796-801.

14. Lessa FC, Nogueira I, Huck C, Hebling J, Costa CA. Transdentinal cytotoxic effects of different concentrations of chlorhexidine gel applied on acid-conditioned dentin substrate. Journal of Biomedical Materials Research B Applied Biomaterials 2010;92:40-7.

15. Giannelli M, Chellini F, Margheri M, Tonelli P, Tani A. Effect of chlorhexidine digluconate on different cell types: a molecular and ultrastructural investigation. Toxicology In Vitro 2008;22:308-17.

16. von Ohle C, Gieseke A, Nistico L, Decker EM, DeBeer D, Stoodley P. Real-time microsensor measurement of local metabolic activities in ex vivo dental biofilms exposed to sucrose and treated with chlorhexidine. Applied and Environmental Microbiology 2010;76:2326-34.

17. Barbour ME, O’Sullivan DJ, Jagger DC. Chlorhexidine adsorption to anatase and rutile titanium. Colloids and
Surfaces A Physicochemical and Engineering Aspects 2007;307: 116-20.

18. Morra M, Cassinelli C, Cascardo G, Carpi A, Fini M, Giavaresi $\mathrm{G}$, et al. Adsorption of cationic antibacterial on collagencoated titanium implant devices. Biomedicine \& Pharmacotherapy 2004;58:418-22.

19. Heling I, Sommer M, Steinberg D, Friedman M, Sela MN. Microbiological evaluation of the efficacy of chlorhexidine in a sustained-release device for dentine sterilization. International Endodontic Journal 1992;25:15-9.

20. Heling I, Steinberg D, Kenig S, Gavrilovich I, Sela MN, Friedman M. Efficacy of a sustained-release device containing chlorhexidine and $\mathrm{Ca}(\mathrm{OH})_{2}$ in preventing secondary infection of dentinal tubules. International Endodontic Journal 1992;25:20-4.

21. Tsibouklis J, Stone M, Thorpe AA, Graham P, Peters V, Heerlien $R$, et al. Preventing bacterial adhesion onto surfaces: the lowsurface-energy approach. Biomaterials 1999;20:1229-35.

22. Lee HJ, Park KD, Park HD, Lee WK, Han DK, Kim SH, et al. Platelet and bacterial repellence on sulfonated poly(ethylene glycol)-acrylate copolymer surfaces. Colloids and Surface B Biointerfaces 2000;18:355-70.

23. Zhang F, Zhang Z, Zhu X, Kang E, Neoh K. Silk-functionalized titanium surfaces for enhancing osteoblast functions and reducing bacterial adhesion. Biomaterials 2008;29:4751-9.

24. Cortizo MS, Alessandrini JL, Etcheverry SB, Cortizo AM. A vanadium/aspirin complex controlled release using a poly( $\beta$-propiolactone) films. Effect on osteosarcoma cells. Journal of Biomaterials Sciences Polymer Edition 2001;12:945-59.

25. Choi J, Konno T, Takai M, Ishihara K. Controlled drug release from multilayered phospholipid polymer hydrogel on titanium alloy surface. Biomaterials 2009;30:5201-8.

26. De Giglio E, Cometa S, Ricci MA, Zizzi A, Cafagna D, Manzotti $S$, et al. Development and characterization of rhVEGF-loaded poly(HEMA-MOEP) coatings electrosynthesized on titanium to enhance bone mineralization and angiogenesis. Acta Biomaterialia 2010;6:282-90.

27. Gower MD, Shanks RA. Acrylic acid level and adhesive performance and peel master-curves of acrylic pressuresensitive adhesives. Journal of Polymer Sciences Part B Polymer Physics 2006;44:1237-52.

28. Le Guéhennec L, Soueidan A, Layrolle P, Amouriq Y. Surface treatments of titanium dental implants for rapid osseointegration. Dental Materials 2007;23:844-54.

29. Rivadeneira J, Barrio D, Arrambide G, Gambino D, Bruzzone L, Etcheverry S. Biological effects of a complex of vanadium(V) with salicylaldehyde semicarbazone in osteoblasts in culture: mechanism of action. Journal of Inorganic Biochemistry 2009;103:633-42.

30. Hunter A, Archer C, Walker P, Blunn G. Attachment and proliferation of osteoblasts and fibroblasts on biomaterials for orthopaedic use. Biomaterials 1995;16:287-95.

31. Lakatos P, Tatrai A, Stern P. Effects of gallium nitrate on calcium transients in UMR-106 rat osteoblastic osteosarcoma cells. Bone 1992;13:379-86.

32. Oberti TG, Schiavoni MM, Cortizo MS. Structure and proporties of poly(benzyl acrylate) synthesized under microwave energy. Radiation Physics and Chemistry 2008;77:597-604.

33. McCarthy AD, Etcheverry SB, Bruzzone L, Cortizo AM. Effects of advanced glycation end-products on the proliferation and differentiation of osteoblast-like cells. Molecular and Cellular Biochemistry 1997;170:43-51.

34. Cortizo MS, Molinuevo MS, Cortizo AM. Biocompatibility and biodegradation of polyester and polyfumarate basedscaffolds for bone tissue engineering. Journal of Tissue Engineering and Regenerative Medicine 2008;2:33-42.

35. Bradford MM. A rapid and sensitive method for the quantitation of microgram quantities of protein utilizing the 
principle of protein-dye binding. Analitical Biochemistry 1976;72:248-54.

36. Cortizo MC, Fernandez Lorenzo de Mele M. Microstructural characteristics of thin biofilm through optical and scanning electron microscopy. World Journal of Microbiology and Biotechnology 2003;19:805-10.

37. Cortizo MC, Fernández Lorenzo de Mele M, Cortizo AM. Metallic dental material biocompatibility in osteoblastlike cells. Conetation with metal ion release. Biological Trace Elements Research 2004;100:151-68.

38. Crank J. The mathematics of diffusion. Oxford: Clarendon Press; 1975.

39. Andreetta HA. Fármacos de Acción Prolongada: Mecanismos de Liberación. Usos de Distintos Modelos. Acta Farmaceutica Bonaerense 2003;22:355-64.

40. Annunziata M, Oliva A, Basile MA, Giordano M, Mazzola N, Rizzo A, et al. The effects of titanium nitride-coating on the topographic and biological features of TPS implant surfaces. Journal of Dentistry 2011;39:720-8.

41. Javed F, Romanos G. The role of primary stability for successful immediate loading of dental implants. A literature review. Journal of Dentistry 2010;38:612-20.

42. Faggion Jr CM, Listl S, Tu Y-K. Assessment of endpoints in studies on peri-implantitis treatment-a systematic review. Journal of Dentistry 2010;38:443-50.

43. Harris L, Tosatti S, Wieland M, Textor M, Richards R. Staphylococcus aureus adhesion to titanium oxide surfaces coated with non-functionalized and peptide-functionalized poly(L-lysine)-grafted-poly(ethylene glycol) copolymers . Biomaterials 2004;25:4135-48.

44. Stewart P, Costerton JW. Antibiotic resistance of bacteria in biofilms. The Lancet 2001;358:135-8.

45. Fernandez Lorenzo de Mele M, Cortizo MC. Biodeterioration of dental materials: influence of bacterial adherence. Biofouling 2000;14:305-16.
46. Diaz C, Schilardi PL, Dos Santos Claro PC, Salvarezza RC, Fernández Lorenzo de Mele MA. Sub-micron trenches reduce the $P$. fluorescens colonization rate on solid surfaces. Applied Materials \& Interfaces 2009;1:136-43.

47. Díaz C, Salvarezza RC, Fernandez Lorenzo de Mele MA, Schilardi PL. Organization of Pseudomonas fluorescens on chemically different nano/microstructured surfaces. Applied Materials \& Interfaces 2010;2:2530-9.

48. Li B, Logan BE. Bacterial adhesion to glass and metaloxide surfaces. Colloids and Surfaces B Biointerfaces 2004;36: 81-90.

49. Montanaro L, Campoccia D, Rizzi S, Donati ME, Breschi L, Prati C, et al. Evaluation of bacterial adhesion of Streptococcus mutans on dental restorative materials. Biomaterials 2004;25:4457-63.

50. Müller R, Eidt A, Hiller KA, Katzur V, Subat M, Schweikl H, et al. Influences of protein films on antibacterial or bacteriarepellent surface coatings in a model system using silicon wafers. Biomaterials 2009;30:4921-9.

51. Cervantes-Uc JM, Vázquez-Torres H, Cauich-Rodríguez JV, Vázquez-Las B, San Román del Barrio J. Comparative study on the properties of acrylic bone cements prepared with either aliphatic or aromatic functionalized methacrylates. Biomaterials 2005;26:4063-72.

52. Harkes G, Feijen J, Dankert J. Adhesion of Escherichia coli on to a series of poly(methacrylates) differing in charge and hydrophobicity. Biomaterials 1991;12:853-60.

53. Baird JA, Taylos LS. Evaluation of amorphous solid dispersion properties using thermal analysis techniques. Advanced Drug Delivery Reviews doi:10.1016/ j.addr.2011.07.009.

54. Kalachandra S, Dongming L, Offenbacher S. Controlled drug release for oral condition by a novel device based on ethylene vinyl acetate (EVA) copolymer. Journal of Materials Science Materials in Medicine 2002;13:53-8. 